\title{
Overutilization of surgery for superficial gastric carcinoma in USA: is it still the case in 2020?
}

\section{(ㄷ)(이우}

\author{
Authors \\ Dennis Yang, Peter V. Draganov \\ Institution \\ Division of Gastroenterology and Hepatology, University of \\ Florida, Gainesville, Florida, United States \\ Bibliography \\ Endosc Int Open 2021; 09: E994-E996 \\ DOI 10.1055/a-1393-5804 \\ ISSN 2364-3722 \\ (c) 2021. The Author(s). \\ This is an open access article published by Thieme under the terms of the Creative \\ Commons Attribution-NonDerivative-NonCommercial License, permitting copying
}

\author{
and reproduction so long as the original work is given appropriate credit. Contents \\ may not be used for commrcial purposes, or adapted, remixed, transformed or \\ built upon. (https://creativecommons.org/licenses/by-nc-nd/4.0/) \\ Georg Thieme Verlag KG, Rüdigerstraße 14, \\ 70469 Stuttgart, Germany \\ Corresponding author \\ Peter V. Draganov, 1329 SW 16th Street, Room \#5254, \\ Gainesville, FL 32608, United States \\ Fax: +1-352-627-9002 \\ peter.draganov@medicine.ufl.edu
}

Gastric cancer is the fifth most common cancer worldwide and the third leading cause of cancer-related death in the world [1, 2]. Given the high incidence of gastric cancer in Asia, rigorous screening strategies have been implemented over the years, resulting in enhanced detection at an early stage. This shift in the timing of diagnosis is critical for prognosis, as early gastric cancers (EGCS) have negligible risk for lymph node metastasis (LNM) [3,4]. Importantly, endoscopic resection can be curative for select EGCs that meet curative resection criteria, as established by the Japanese Gastric Cancer Association (JGCA) [5]. When compared to surgery, endoscopic resection for EGCs in Asia is associated with similar oncological outcomes, yet it is a less invasive stomach-preserving technique with improved quality of life [6]. Hence, ESD has become the standard of care for EGCs in Asia, with an increasing interest in the West over recent years.

In this issue of Endoscopy International Open, Barakat et al retrospectively analyzed the rates of endoscopic and surgical resection in the United States for EGCs that meet the JGCA absolute and expanded curative resection criteria [7]. The authors used data on gastric cancers collected from the Surveillance, Epidemiology and End Results (SEER) database from 2010 to 2015. During this period, 161,854 gastric cancers were identified, of which 2219 were EGCs (1074 T1a and 1145 T1b lesions). Data on the type of resection were available for 1733 of these EGCs. Overall, 304 lesions (17.5\%) were treated endoscopically while $1430(82.5 \%)$ were surgically resected $(P=$ $0.0001)$. The proportion of EGCs resected endoscopically versus surgically was higher if they met the JGCA absolute criterion (T1a, well-differentiated, $<2 \mathrm{~cm})(26 \%)$, as compared to other expanded criteria (9\%-14\%). Temporal analysis from 2010 to
2015 showed a near 3-fold increase in endoscopic resection for EGCs and a concomitant and proportional downtrend in surgery. Lastly, the authors reported comparable survival rates between the two treatment modalities based on Kaplan-Meier analysis.

Barakat et al. should be congratulated for performing a large US population-based study evaluating resection trends for EGCs. Overall, the authors show that surgery remains overwhelmingly the predominant practice for the management of EGCs in the United States, albeit the rate of endoscopic resection has slowly increased. Gastric cancer is one of the leading causes of cancer-related morbidity and mortality. Given its notoriously low survival rates, early detection and resection is the most effective strategy to improve prognosis. Yet, as demonstrated by this study, of the 161,854 gastric cancers identified in the SEER database from 2010 to 2015, only a dismally low $2219(1.37 \%)$ were EGCs, further highlighting that most gastric cancers in the United States are diagnosed in late stages. This is in stark contrast to Asia, where systematic gastric cancer screening efforts have increased rates of early detection and improved survival. It should be noted that the estimated number of new cases of gastric cancer per year in the United States, including 2021, is higher than the number of new cases of esophageal cancer [8]. Yet, there are no guidelines for gastric cancer screening as opposed to those established for Barrett's esophagus and esophageal cancer. While mass gastric cancer screening may not be cost-effective in the United States implementation of targeted screening of high-risk populations (i.e. immigrants from high-incidence region, family history of gastric cancer) may increase the detection of EGCs suitable for endoscopic resection without the need for surgery [9]. We 
should emphasize that systematic and detailed examination of the stomach is a prerequisite for endoscopy to be an effective tool for gastric cancer screening. The lack of defined quality metrics for upper endoscopy in the United States is associated with variability in clinical practice and presumably the notoriously high rates of missed gastric cancers at endoscopy reported in the West [10]. Increasing awareness of gastric cancer, establishing a structured training system for endoscopists and quality assurance for endoscopy are essential for more successful detection of EGCs [11-13].

According to this study, most of the EGCs in the SEER database were managed surgically as opposed to endoscopic resection ( $82.5 \%$ versus $17.5 \%$; $P=0.0001)$. Several potential explanations may account for these findings. For one, the limitations of endoscopic mucosal resection (EMR) for the management of EGCs are well recognized. When compared to ESD, EMR is associated with a very high rate of incomplete resection, even for EGCs $<20 \mathrm{~mm}$ [6]. Hence, ESD has long replaced EMR as the standard method in Asia, accounting for over $90 \%$ of endoscopic resections for EGCs in Japan [4]. Secondly, the study captured data from 2010 to 2015, a period in which the US ESD experience was limited. In fact, a survey analysis by our group around this time confirmed that most US endoscopists training in ESD had yet to incorporate this technique into their clinical practice [14]. Nonetheless, with the increasing availability of dedicated ESD devices, accessories, and structured training courses, we have witnessed increasing adoption of this technique in recent years, as suggested by the upward trend in endoscopic resection for EGCs reported in this study. Furthermore, it is worth noting that some studies from the West have suggested a higher rate of LNM in EGCs as compared to data originating from Asia, leading to the speculation of differences in biological aggressiveness of EGCs in the West [15]. Nonetheless, the discrepantly higher rate of LNM reported in the West as compared to Asia appears to be primarily driven by lesions meeting the expanded criteria, whereas EGCs within the absolute criteria have been associated with excellent outcomes and negligible risk for LNM $[16,17]$. Hence, not surprisingly, most of the endoscopic resections for EGCs reported in this study were for lesions meeting the absolute criteria; albeit it remains unclear how precise histopathological staging was obtained from the SEER database, particularly for the non-surgical specimens. Noteworthy, histological evaluation of endoscopic and surgically resected specimens in Japan is routinely performed in a far more systematic and detailed manner when compared with specimen handling in the West $[15,18]$. As the practice of ESD continues to grow in the United States, we need to embrace the same meticulous approach to lesion characterization and histological staging from our Asian counterparts to ensure best practices and avoid misclassification of more advanced disease and risk for LNM.

The study by Barakat et al points towards the current reality in the United States: surgery remains overutilized for the treatment of EGCs. Nonetheless, caution should be exercised when interpreting these findings, given the well-recognized limitations of a population-based study utilizing the SEER database, including: missing data (i.e. data on resection type was only available in a subset of patients with EGCs), coding reliability (i.e. histopathology), and selection bias when evaluating longterm outcomes after cancer-directed therapy. Yet, it is clear that efforts to increase the detection of EGCs must be an ongoing point of emphasis. Equally as important, we need to raise awareness of endoscopic resection, specifically ESD, as the primary modality for most EGCs. At this point, multiple studies from the West have corroborated the feasibility and safety of ESD for the treatment of dysplastic lesions and EGCs when performed at centers with the appropriate expertise $[16,17,19]$. Our ultimate goal should be to provide patients with appropriate stage-specific therapy based on well-established criteria. Barakat and colleagues suggests that endoscopic therapy for EGC in the United States may be trending in the right direction, albeit the gap with surgery is still wide and much work remains to be done.

\section{Competing interests}

Dr. Yang is a consultant for Boston Scientific, Lumendi, and Steris. Dr. Draganov is a consultant for Olympus, Boston Scientific, Cook Medical, Lumendi, Steris, Medtronic, and Microtech

\section{References}

[1] WHO International Agency for Research on Cancer. Cancer Today. Available online (Accessed 29.01.2021): http://gco.iarc.fr/today

[2] Ono H, Kondo H, Gotoda T et al. Endoscopic mucosal resection for treatment of early gastric cancer. Gut 2001; 48: 225-229

[3] Chung IK, Lee JH, Lee SH et al. Therapeutic outcomes in 1000 cases of endoscopic submucosal dissection for early gastric neoplasms: Korean ESD Study Group multicenter study. Gastrointest Endosc 2009; 69: 1228-1235

[4] Fujishiro M, Yoshida S, Matsuda R et al. Updated evidence on endoscopic resection of early gastric cancer from Japan. Gastric Cancer 2017; 20: 39-44

[5] Japanese Gastric Cancer Association. Japanese gastric cancer treatment guidelines 2018 (5th edition). Gastric Cancer 2021; 24: 1-21. doi:10.1007/s10120-020-01042-y

[6] Ono H, Yao K, Fujishiro M et al. Guidelines for endoscopic submucosal dissection and endoscopic mucosal resection for early gastric cancer. Dig Endosc 2016; 28: 3-15

[7] Barakat M, Ramai D, Cheung D et al. Management of early gastric cancer meeting criteria for endoscopic resection: US populationbased study. Endosc Int Open 2021; 09: E989-E993

[8] American Cancer Society. Cancer Facts and Figures 2021. Available online (Accessed 30.01.2021): https://www.cancer.org/content/ dam/cancer-org/research/cancer-facts-and-statistics/annual-cancerfacts-and-figures/2021/cancer-facts-and-figures-2021.pdf

[9] Huang RJ, Hwang JH. The management of gastric intestinal metaplasia in the united states: a controversial topic. Gastroenterology 2020; 159: 402-403

[10] Pimenta-Melo AR, Monteiro-Soares M, Libanio D et al. Missing rate for gastric cancer during upper gastrointestinal endoscopy: a systematic review and meta-analysis. Eur J Gastroenterol Hepatol 2016; 28: 1041-1049

[11] Park WG, Shaheen NJ, Cohen J et al. Quality indicators for EGD. Gastrointest Endosc 2015; 81: 17-30 
[12] Chadwick G, Groene O, Riley S et al. Gastric cancers missed during endoscopy in England. Clin Gastroenterol Hepatol 2015; 13: 12651270

[13] Delgado Guillena PG, Morales VJ, Ramiro MJ et al. Gastric cancer missed at esophagogastroduodenoscopy in a well-defined Spanish population. Dig Liver Dis 2019; 51: 1123-1129

[14] Schlacterman A, Goddard A, Yang D et al. Perspectives on endoscopic submucosal dissection training in the United States: a survey analysis. Endosc Int Open 2018; 6: E399-E409

[15] Yang D, Draganov PV. Endoscopic submucosal dissection for early gastric cancer in the West: the absolute but not final word. Gastrointest Endosc 2019; 90: 480-482

[16] Hanada Y, Choi AY, Hwang JH et al. Low frequency of lymph node metastases in patients in the United States with early-stage gastric cancers that fulfill Japanese endoscopic resection criteria. Clin Gastroenterol Hepatol 2019; 17: 1763-1769

[17] Ngamruengphong S, Ferri L, Aihara $\mathrm{H}$ et al. Efficacy of Endoscopic Submucosal Dissection for Superficial Gastric Neoplasia in a Large Cohort in North America. Clin Gastroenterol Hepatol 2020; 18 : S1542-3565(20)30834-X. doi:10.1016/j.cgh.2020.06.023

[18] Abdelfatah MM, Barakat M, Othman MO et al. The incidence of lymph node metastasis in submucosal early gastric cancer according to the expanded criteria: a systematic review. Surg Endosc 2019; 33: 26-32

[19] Probst A, Schneider A, Schaller T et al. endoscopic submucosal dissection for early gastric cancer: are expanded resection criteria safe for Western patients? Endoscopy 2017; 49: 855-865 